\title{
"Batavia": An Analysis on the Pedagogical Possibilities and Limitations of Virtual Reality Art
}

\author{
Anand Sergeant
}

\section{Introduction}

$\mathrm{M}_{\mathrm{l}}^{\mathrm{s}}$ USEUMS, and the works that they contain, have long been perceived and utilized as spaces for public pedagogy, historical representation, and critical thought. Many important pedagogical thinkers of old, such as Jerome Bruner, Maria Montessori, and John Dewey emphasized the importance of the arts in education, and this perspective is widely held today (Mastandrea and Maricchiolo, 18-19). Specifically, much work has examined the role of museums and their art in the formation of attitudes, identities, and perspectives of social groups and their histories (Borg and Mayo; Liu and Hilton; Coffee). In this paper, a particular emphasis will be placed on this formative role of works of art, specifically, in terms of their historical representations and the ways in which they may educate public audiences.

As educational scholars Carmel Borg and Peter Mayo describe, the museum plays a crucial role in legitimizing, representing, and defining what counts as "official knowledge" (25). Regarding history, a key component of this role is deciding which stories or representations are included and remembered, and which, instead, are hidden and forgotten (Borg and Mayo, 35). For instance, many museums in the West tend to focus on the perspective and the biased experiences of the 'high-brow'-ignoring and erasing the histories of violence and struggle experienced by marginalized groups (Borg and Mayo, 42-43). In this way, these institutions can serve as a reinforcement of and means to propagate colonial narratives; many art museums disproportionately depict the voices and the stories of the ruling forces. In doing so, museums often disregard and fail to educate the public on the "history, voices, and standpoints of the subaltern"
(Borg and Mayo, 38). Importantly, this disproportionate representation can breed prejudice and a lack of public awareness regarding historical colonial injustices - justifying further colonial and neocolonial practices in the present. As Liu and Hilton describe: "Representations of history help to define the social identity of peoples, especially in how they relate to other peoples and to current issues of international politics and internal diversity" (537). Historical narratives, and the ways in which they are socially represented, play important roles in justifying the current circumstances and class of social groups, and informing our current responses to political and social challenges (Liu and Hilton, 538).

Important aspects of these historical representations are the ways that they are produced and displayed to the public. As art techniques, technologies, and representations change, the uses and social implications of artworks are complicated as well. In his 1967 text, What is Cinema?, André Bazin describes the ways in which the invention of photography and photographic art techniques served to fulfill society's deep need for realism, which allowed other art forms to focus on alternative creative depictions (160-162). This fundamentally changed artistic purpose and practice. Similarly, in his seminal text, The Work of Art in the Age of Mechanical Reproduction, Walter Benjamin describes the shifting nature of art following the creation and use of technologies which enabled mechanical reproducibility (668-669). These theorists demonstrated the incredible shaping effects that novel artistic technologies can have on human artistic representation - and the ways in which these representations are experienced and analyzed by their audience. 
An important form of modern artistic production and representation that is currently being implemented in museums around the world is the use of Virtual Reality (VR) technologies and experiences. Virtual Reality art technologies allow a viewer to immerse themselves in a multi-sensory, virtual world by use of a large headset, which enables participants to "manipulate and interact with the simulated environment" (Kelley and Tornatzky, 2). VR technologies differ profoundly from previous artistic representational technologies because the traditional roles of creator and viewer are blurred; the virtual reality experience involves the active participation of the user in the creation of the virtual reality content as they make decisions and immerse themselves in the three-dimensional simulation (Kelley and Tornatzky, 1-2). As virtual reality headset costs have decreased, these devices have become increasingly commonplace in museums. For example, the National Museum of Finland recently introduced The Opening of the Diet 1863 by Alexander II - a virtual experience which enables viewers to step inside one of the museum's paintings, interact with important characters, and explore the Finnish political state of the 1860s (HillsDuty). Further, in an effort to "bring lost worlds back to life," Beijing's Forbidden City "takes visitors through reconstructions of the porcelain factories during the Ming and Qing dynasties" (Gannon).

A particularly interesting application of these VR technologies used as artistic, immersive depictions of history is the 'Batavia' VR experience that has recently been introduced at the Westfries Museum in the Netherlands. The exhibition celebrates 400 years since 'Batavia', a colonial name of Indonesia's capital city, Jakarta, was colonized by the Dutch in the early 1600s. Inspired by a map of Batavia from 1627 that was discovered and since held by the museum, the VR exhibit allows up to 30 visitors at a time to experience the old city using special VR glasses ("Batavia 1627 in Virtual Reality"). Visitors are taken on a threedimensional, simulated, reconstructive tour through the city with narration from the original map maker, Floris van Berkendrode. Further, visitors can choose to 'land' somewhere in the city, to witness the city's various aspects close up and learn about its history (Sidarto). The exhibit offers an interesting example of the possibilities of immersive artistic experiences to connect viewers with significant historical periods, through the use of virtual reality headset technolo- gies. However, the 'Batavia' exhibit has also been criticized for its glorification of a colonial past; it has been said to disregard important counter-histories of struggle and destruction experienced by the native Indonesian people (Sidarto).

Several aspects of 'Batavia' make it a particularly interesting case-study of modern VR art technology. Firstly, 'Batavia' is one of the most advanced examples of VR art technologies to date. While many VR exhibits in museums allow visitors to view threedimensional virtual objects or artifacts, very few allow the visitors to shape their own experiences (i.e. choosing where to land and what to see) the way that 'Batavia' allows. As such, 'Batavia' serves as a relevant example of the current limitations and possibilities of VR art technologies, and creates a rich site for analysis due to its technological advancement. 'Batavia' also speaks to Indigenous historical representation, which is an extremely important and relevant issue in many countries of the world today, including Canada. Canada's brutal colonial history and continued suppression of Indigenous stories and epistemologies - a trend which is common in many colonized nations - has reinforced colonial dominance and threatened Indigenous languages and culture (Reyhner and Singh). The 'Batavia' exhibit represents the Dutch colonization of Indonesia, which makes it an important focus of study due to its relevance to these issues of colonialism. The exhibit's depiction of colonial history has important implications for Indonesian Indigenous peoples and colonial attitudes towards them. As such, it will be important in setting a precedent for future VR technologies in other countries which represent colonial and Indigenous histories. Finally, my research into 'Batavia' found that there was a fairly uncritical response to the exhibit in the media, and the museum did not seem to critically and fully address the ethical concerns regarding the project and its representation of colonialism (Sidarto; "400 Jaar Batavia"). 'Batavia' seemed to induce large excitement and celebration (it celebrates the $400^{\text {th }}$ anniversary of Batavia's colonization) in the Dutch media, which made a more balanced critique of the exhibit even more importantI firmly believe that novel pedagogical technologies must be heavily scrutinized before they become normalized.

In this paper, I will examine the question: what are the ways in which virtual reality technologies 
complicate the narrative and representational capabilities of art as a pedagogical tool for history? To do so, I will first explore the immersive, active, and multi-sensory platform that VR provides to the viewer, and the ways that this technology might influence how historical representations can be engaged with and learned from. I will then consider notions of aura and objectivity in relation to VR art technologies, to explore some of the drawbacks and sociopolitical implications of these new art forms. I argue that while the immersive and engaging form of VR technologies may offer some interesting possibilities as an educational practice for history through art, if they are not used properly, VR-art technologies may serve to propagate colonial narratives and inhibit a critical lens on historical events. I will draw on the specific case-study of the Westfries museum's 'Batavia' exhibit throughout the paper.

This paper involves the integration of theories of pedagogy, technology, and art. I was first intrigued by these relationships when I visited several local museums in southern Ontario which have begun to incorporate VR artworks in their exhibitions, and upon further research I noticed that this is a largely untouched area of study. As an academic I have a keen interest in the ways in which pedagogy transcends the classroom. It is often forgotten how educationally influential institutions such as museums can be, and thus I believe that applying pedagogical research with the use of novel technologies in these institutions could be a valuable addition to existing academic work. 'Batavia' served as a unique example of the intersections between pedagogy, art, and technology, and the ways that this intersection can be hugely influential socially and politically.

Studying these relationships also posed some challenges. Virtual reality has only recently been incorporated in educational settings, which made the analysis of its efficacy as a pedagogical tool more difficult. Further, museums are not always viewed as defining sites for pedagogy and public thought regarding historical events, which reduced the amount of existing research on this matter. Finally, I was never able to personally attend the Westfries museum during the creation of this project. While I have spoken to several visitors of the museum and the 'Batavia' exhibit, it certainly would have helped my work to gain more of a first-hand experience. These sorts of challenges affirmed the importance of drawing on multiple per- spectives and taking an interdisciplinary approach for this project. By drawing from work involving pedagogy, technological theory, and historical representations, it was more feasible to critically negotiate with the gaps in the current literature. Thus, the interdisciplinary nature of this project was crucial in hurdling some of the methodological and informational barriers that were inevitable in such a novel scholarly field.

\section{The VR Art Experience}

Perhaps the most striking and novel aspect of VR art is the way in which VR technologies fundamentally change the art experience for the user. In contrast to traditional museum art media, such as paintings, sculptures, or short films, where the viewer is inherently separated from the artwork and the creator, VR art allows a more participatory, physically immersed engagement with the art. As electronic artists Brendan Kelley and Cyane Tornatzky describe, contemporary VR headsets have both positional and gyroscopic sensors, which, by communicating with a computer, allow the VR program to update the user's virtual position based on their action and position in the real world (3). This allows for an intimate connection between the user and the artwork that they are experiencing - the user is able to make (at least partial) decisions during their interaction with the art. The user chooses what they want to see and can personalize the artistic experience, blurring the lines between the creator and the user. Audience members are able to "look beyond two-dimensional surfaces and perhaps even enter into the mind of creators" due to the participatory nature of VR art (Kelley and Tornatzky, 3). This creates a unique, and very active artistic and pedagogical experience for the audience.

The personalized, active art experience is furthered by the multi-sensory elements of VR technologies. Through the VR headset, the user is immersed in a multi-sensory, three-dimensional experience which contains visual, auditory, and somatosensory elements. Users' movements are tracked by various sensors, and this data corresponds to users' activities in the simulation (Kelley and Tornatzky, 3). These elements of VR artistic technologies create a far more holistic experience for the VR user, and allow them to experience and engage with artwork in a more extensive and interactive manner.

Westfries' 'Batavia' is a pertinent example of 
these more personalized, multi-sensory artistic experiences produced by VR art exhibits. In the exhibit, users fly through three-dimensional scenes of the city while hearing sound effects and a historical narration. By looking at certain marked points in the virtual world, the visitor's virtual self is able to travel in that direction and is subsequently told more about a specific aspect of Batavia ("400 Jaar Batavia"). The viewers thus engage with an immersive and multi-sensory experience in which they have a certain amount of autonomy regarding their particular engagement with the art. How, then, does the active, multi-sensory and immersive experience of art created by VR technologies complicate the pedagogical possibilities of historical representations, and what are the implications of this complication?

\section{Pedagogical Possibilities}

An important aspect of the pedagogical experience of VR art technologies is the more active, experiential participation that they create. According to Mary Wright, who discusses the short-term educational benefits of experiential learning, personal experiences can facilitate more active interest in educational content, and can lead to better understandings of abstract sociological connections in students (117). VR-specific research has also demonstrated the ways in which active VR modelling technologies have shown benefits in the visualization of information and giving "abstract concepts concrete form" compared to learning the same information through a textbook (Eggarxou and Psycharis, 120). This sort of research points to an interesting potential for VR artists to create more experiential and involved artistic experiences. Rather than the traditional observational learning which distances the viewer from the art piece, VR art allows the viewer to take a far more active and experiential role in the art, potentially enabling the viewer to learn and understand artistic representations of history on a more profound level. These VR technologies could seemingly allow users to gain deeper and more personally relevant understandings of artistic depictions - as suggested by the literature on experiential learning - compared to more observational and traditional forms of art such as paintings, sculptures, or photographs. The experiential aspect of VR art, then, could provide a pedagogical advantage for viewers, in their learning of history through art.
In the 'Batavia' exhibit, for instance, the multisensory, immersive VR environment of the old town, and the participatory elements of the exhibit may offer benefits as a pedagogical tool for Dutch colonial history. Rather than an observation and analysis of the ancient map of Batavia, which is what previously constituted this portion of the Westfries museum, the 'Batavia' VR experience thrusts the audience into a much more experiential involvement with the art and the depicted history. This active immersion could provide viewers with the suggested benefits of a more experiential pedagogy - namely, a clearer understanding of Dutch and Indonesian history and the ability to visualize and ground abstract historical information regarding this old town in an immersive educational experience. This speaks to the potential transformative nature of VR when it comes to historical representation and pedagogy. As discussed previously, art can play a huge role in shaping cultural attitudes towards historical events, and defining social identities in relation to history and the present (Borg and Mayo; Liu and Hilton). Thus, in experiencing the 'Batavia' exhibit, the conceptions of the Dutch public in relation to their colonial past could plausibly be more vividly revealed, clarified, and critically questioned-potentially inducing a phenomenon that Liu has identified as "value threat... [when] the morality of the group has been called into question by historical misdeeds" (Liu, Hilton, 546). Through a more active and experiential pedagogical experience, the colonial past of the Dutch people may be more thoroughly examined, and provoke visitors to examine Dutch history more actively and critically.

Work has also been conducted on the potential of virtual reality to make learning more engaging and motivating for the user - another possible pedagogical benefit of these technologies. Freina and Ott's 2014 review of the uses of immersive virtual reality experiences in education reported on a diversity of studies demonstrating the advantages of virtual reality in "increasing the learner's involvement and motivation" due to the multi-sensory, 'authentic' simulations $(2,6)$. These findings suggest a significant benefit of VR in the domain of museum learning. Research has demonstrated that visitors typically spend "less than 15 minutes in any museum gallery," which "diminishes the chances for sustained inquiry or narrative" regarding the artwork; creating incomplete 
educational experiences which likely do not optimize the museum's pedagogical capabilities (Bartels and Hein, 40). Further research has also suggested that museums are not attracting many young individuals today, due to a lack of curiosity, and a sense of boredom associated with these institutions (Mastandrea and Maricchiolo, 5-6). Thus, VR art's ability to create immersive, more engaging, and 'fun' art experiences - in some ways gamifying the experience of art - may serve to encourage increased engagement with the art from the public, especially in young populations. For example, in the 'Batavia' exhibit, rather than studying an old map of the town, and reading blurbs regarding its history, it is plausible that the new, multi-sensory 'journey' through the old town involving an engaging narrative by a famous historical figure could promote increased user engagement with the artwork. Clearly, coupled with the potential pedagogical benefits of a more experiential learning opportunity, this use of VR art to depict history could provide a very potent mechanism for public pedagogy regarding Dutch colonial history.

\section{Drawbacks and Considerations}

Yet, though virtual reality artworks offer interesting pedagogical possibilities for art institutions, they also come with important considerations and drawbacks that must be analysed carefully. For instance, though VR technologies may provide an engaging and amusing environment that may motivate more viewers to experience the exhibit, the gamification of the learning environment could undermine the importance of true critical thought and reflection following the experience of the art. As Wright describes, successful experiential learning requires establishing the learning expectations from the outset of the experience (preparation), and a critical reflection following the experience (Wright, 118-119). Establishing the educational goals of a VR art experience such as 'Batavia' before users enter the simulation, and a post-simulation critical reflection of what the users learned may be necessary to truly reap the benefits of the immersive and engaging art experience. This raises an interesting tension, because while the gamification of art exhibitions through VR may promote more user interest and participation, it may simultaneously undermine the educational benefits of historical representations through art by failing to add the necessary educational context to the experiences.
This tension can be explored further through a comparison with Walter Benjamin's discussion surrounding the ways in which the introduction of cinematic technologies complicated notions of art contemplation and absorption. To Benjamin, while the static structure of a painting invites the viewer to contemplate and be truly absorbed by the work of art, the multi-sensory and constantly moving film continuously interrupts the viewer's process of contemplation and association (682-683). Since the film is constantly interrupting the viewer's train of thoughts with moving images, even though the viewer is in the position of the critic, the viewer "is an examiner, but an absent-minded one" (Benjamin, 683). The overstimulation and ever-changing notion of the film technology thus promotes the treatment of art as something that is distractedly absorbed by the public, rather than something that itself absorbs viewers and can potentially promote critical thought (Benjamin, 683). In relation to VR, Benjamin's analysis of film raises questions concerning how the shift to virtual reality technologies and their immersive, game-like simulations may affect an audience's ability to really engage critically with the VR's historical representation. In exhibits like 'Batavia', users do not have much time to stop and critically reflect on the histories they are experiencing - the experience involves a near-constant narration and moving journey through the old town, full of sensory stimulation. As described in Wright's work, the use of more experiential learning is generally only useful when it is coupled with a critical reflection on the experience. If, then, VR art experiences - which offer similar if not more constant changes and stimulations than Benjamin describes in films - do not allow viewers to critically analyze the work and the significance of the displayed history, their benefits as experiential learning experiences may be undermined.

Another useful mechanism by which to examine the pedagogical experience of VR art is Benjamin's notion of 'aura', which is complicated by modern VR art technologies and representations. To Benjamin, the unique existence of an original, authentic work such as a painting or sculpture gives it a sort of 'aura,' which embeds the artwork in tradition, and imbues upon it a cult-like, ritualistic value (Benjamin, 668670). In the age of mechanical reproduction, however, as art-forms such as photography and film are reproduced and recreated, the original works begins 
to lose their aura, which frees them from their connection to ritual (Benjamin, 670-671). In this way, reproducible art forms can take on a more widely accessible, political role; in the absence of an aura or ritualistic value, the artwork can be critically analyzed and viewed with more of a socio-political significance (Benjamin, 671). In relation to VR, on one hand, VR art technologies and experiences are extremely reproducible; for instance, the Batavia exhibit allows 30 viewers at once to experience the exhibition, and could quite easily be replicated in other artistic institutions. In this way, the aura that has the potential to emanate from a uniqueness in space and time is undermined through its reproduction, both spatially and temporally - removing the distance and unapproachability of the art from the audience (670). This would then suggest that VR art, similar to other reproducible art forms such as photographs and films, could exist free from a cult-like value which generally precludes a critical examination of the artwork from the audience. VR art could potentially, then, serve broader political purposes regarding historical representations and pedagogy. By rejecting the unexamined ritual-like notion of art, and allowing for a more reproducible accessibility, VR art could encourage a more widespread public discourse regarding histories such as Batavia.

However, one could also argue that VR art experiences, which are controlled by and shaped by each individual user in slightly different manners, do actually offer unique and personalized art experiences. VR art exhibits, such as 'Batavia', allow participants to immerse themselves in the artwork, and make decisions regarding their specific experiences of the artin some ways forming a unique existence of the art piece in time and in space. While VR art is certainly more accessible and reproducible than art forms like paintings and sculptures, it may still involve a sort of 'aura,' created by the unique and personalized multisensory experience offered by the art. Research has demonstrated the ability for immersive VR to produce moving emotional experiences through the use of "imagery, sound, story, and meaningful interaction" (Goslin and Morie, 100). In this sense, the awe-like sentiment experienced by a user of these VR art technologies may, as suggested by Benjamin, actually discourage a critical appraisal of the work's content. The aura produced from unique VR experiences depoliticizes the art because of the emotional, cult-like value of the experience which distracts viewers from critically examining the content of the art piece. For example, in the Westfries' 'Batavia', the goal of the artwork is to provide visitors with an engaging art experience, while simultaneously teaching visitors about an important piece of Dutch colonial history in Indonesia. Yet, while the VR art may entice users with its appeal as a unique, personalized, multi-sensory experience, the produced emotional 'aura' may, as Benjamin describes with traditional art forms, actually serve to distract users away from the political significance of the history it represents.

This challenges the sentiments of some art curators, such as Bruno David from the National $\mathrm{Mu}-$ seum of Natural History in Paris, who believes that VR art is not a threat to other forms of art such as paintings because "people are coming to a museum to see real objects because real objects are emotional" (Coates). On one hand, there is a sentiment that artwork viewed through replaceable forms of technology cannot offer the sort of 'aura' that more traditional forms of art can provide. However, as was discussed, research demonstrates the ability of VR to produce moving emotional experiences, and these unique and personalized experiences may confer a ritualistic aura on the art. Here, it is important to recognize the ways in which VR art technologies blur dichotomous notions of aura. VR art exhibits such as 'Batavia' offer, perhaps, a possibility to simultaneously produce original and emotional experiences for the audience, while also enabling the artwork to be a reproducible and collaborative art experience. For education, the aura and unique experience offered by these artworks must be considered closely; a balance must be struck between the extent to which these experiences can entice viewers, and the extent to which necessary pedagogical context is included. Perhaps, then, these exhibits can harness both the enticing emotional response evoked by the artwork, and the political and pedagogical possibilities of this reproducible experience.

\section{VR Objectivity}

It is clear that, when used properly, VR art could offer intriguing pedagogical possibilities for historical representations. However, this discussion rests on the assumption that these art forms actually offer a balanced and accurate depiction of the history that 
occurred. VR art exhibits such as 'Batavia' are being sold as realistic and accurate depictions of earlier historical periods and events, which makes the examination of their objectivity even more important ("Batavia 1627 in Virtual Reality"). While artworks such as paintings and sculptures can be assumed to contain personal and political biases from the artist, historical VR art exhibits in many ways assume a realistic and 'true' depiction of the past. As Bazin described with photography, the affirmation of photographs as the most accurate representations of reality legitimized photographs as representations that transcended time and depicted historical events objectively (162). The attitude of realism surrounding current VR art exhibitions such as 'Batavia'which is sold as being "as accurate and detailed as possible" - similarly implies a sort of objectivity to these VR art forms; viewers enter the simulation expecting an objective depiction of the past (Sidarto).

There are several concerning aspects about this attitude of realism towards virtual 'reality' technologies. If they do not represent historical times appropriately and fairly, they could serve to delegitimize other, 'less accurate' art forms that may represent important histories of struggle and injustice experienced by marginalized groups. Similar to the way that the increased objective credibility given to photography stripped other traditional art forms of their authority, VR art depictions of history and their assumed 'improved' representations of the past may delegitimize and suppress important art depicting the perspective of marginalized groups.

For example, the 'Batavia' exhibit has been criticized for 'glorifying' the colonial history of Batavia by failing to demonstrate and critique the structural violence towards the native Indonesian people or the suffering of slaves which occurred throughout the brutal Dutch destruction of the old city in 1619 (Sidarto; Kehoe, 5). As Kehoe describes, the city of Batavia was built in a way such that "Dutch residents could dominate the other ninety percent of the population," including the 13000 slaves (18-19). Moreover, as Bayuni asserts, Indonesian people today have questions about their history as they know their ancestors "were killed, tortured, raped... and stripped of all dignity of human beings," yet there is very little literature available in Indonesia or the Netherlands on these topics (Bayuni). This affirms the importance for 'Batavia', which is supposedly an accurate depiction of history with historical authority, to represent more holistic and objective depictions of Indonesian perspectives. If it does not do so, Indonesian histories of struggle and subjugation will be further marginalized, especially if 'Batavia' is offered in Indonesia down the road-as Westfries museum director Ad Geerdink hopes (Sidarto).

Despite being criticized for propagating a revisionist history, the creators of the 'Batavia' exhibit insist that the program does discuss these colonial misdoings, "just not in a judgemental way, but rather in a presentational way" (Sidarto). Yet, the presentation of colonial wrongdoings without depicting the true emotional and physical suffering they created cannot do justice to the experiences of the marginalized, nor does it offer any critical lesson for reconciliation or future colonial action. As Mamdani describes, post-colonial story-telling and biography can influence present understandings regarding past injustices and can create the assumption of a neutral, anti-colonial identity (602-603). 'Batavia' thus sets a dangerous precedent for the future possibilities of these VR historical depictions, and the ways in which these depictions may fail to represent important colonial narratives under the guise of objectivity. These marginalized narratives are crucial for developing a critical historical pedagogy through art. 'Objective' representations of histories that fail to include colonial brutality can serve to propagate dominant settler discourses and interfere with the ability to promote reconciliation and decolonization through education.

\section{Recommendations}

There are several key elements, then, which must be negotiated with and implemented in future educational VR art exhibits to ensure that the representations are portrayed accurately, and audiences are able to receive productive pedagogical experiences. Though 'objectivity' is a difficult goal to define due to its subjective and changing nature, creators of VR art exhibits must create their artworks with a conscience of the artwork's socio-political implications, and demand several questions of their work throughout the production process. When considering a historical representation through VR, I argue the creators must ask themselves the following questions: What are we trying to depict? What does the depiction imply? Through what perspective are we telling the story and what perspectives are missing? By asking these 
questions, creators would be forced to consider the implications of the artwork on a socio-political level, and reflect on the biases that are present in the narration of their stories. This could greatly minimize the production of harmful colonial content. For example, had these questions been asked in the production of 'Batavia', producers would have likely realized that the exhibit demonstrates a glorified colonial history largely through the Dutch colonial perspective, which is bound to reify and justify colonial attitudes and practices. By demanding these questions, and including the missing perspectives of the Indigenous Indonesian people who suffered greatly from these colonial endeavours, the audience could be enlightened on the darker aspects of colonialism and the histories of struggle and oppression that existed. By experiencing both perspectives of the story in the VR exhibit, participants would not only learn about the history of powerful nations and the damage promoted by colonialism, but also the ways that colonial processes can be romanticised to justify continued oppression in the present. Engaging with the socio-political implications of their work in the production process would allow creators and museum curators to produce far more accurate, holistic, and pedagogically beneficial artworks in the future.

Finally, in the presentation of artworks, I argue that museums must ensure that audiences are adequately prepared before their experience on the artwork's significance, and that audiences are encouraged to critically reflect on the artwork after their experience. This recommendation is based on Mary Wright's research on experiential learning discussed earlier in this paper, which describes initial preparation and post facto reflection as crucial for optimizing experiential learning opportunities (Wright, 118119). In an exhibit such as Batavia, this could consist of priming the audience before the experience on the historical significance of the colonization of Batavia, and encouraging them to reflect after the exhibit on the colonial experience of the various perspectives depicted. In this way, museums can strike the right balance between the enticing aura of the work and its social and political significance - ensuring that audience members are able to think more critically about the artwork, and understand that the depicted history is not just a 'fun VR game' but depicts relevant historical information.

Some may argue that these sorts of precautions are overly imposing on audiences in museums, and that they may ruin the freedom or enjoyment of customers. However, if museums wish to present biographical depictions of history which have significant social and pedagogical implications, they retain a responsibility to ensure that these depictions are presented accurately, and that the audience is able to think critically upon them.

\section{Conclusion}

Art displayed by public institutions greatly affects public education, attitude formation, and historical representations, which often inform current responses in the social and political sphere. In this paper, I analyzed the ways in which novel VR art technologies and depictions complicate public art's pedagogical capabilities for history education. VR art technologies present intriguing possibilities for the future of artistic pedagogy by offering an interactive, emotional, and multi-sensory experiential platform from which viewers can learn, and understand more completely, important colonial histories. However, the implementation of these technologies must be done with caution; the gamification and 'aura' of these technologies may lead to an uncritical pedagogical experience, which could serve to treat VR art as a form of entertainment and neglect marginalized historical narratives. The analysis of 'Batavia', a contemporary example of VR art technology which represents Dutch colonial history, demonstrates the importance of a careful implementation of these technologies. The ability of VR art to act as an objective authority of the past could, potentially, serve to propagate and reinforce dominant colonial narratives, which would be detrimental to decolonization and reconciliation processes. Going forward, it is crucial to responsibly acknowledge the pedagogical implications of novel art technologies and experiences, by critically analyzing who is telling the stories, what the stories may imply, and their socio-political implications. 
Anand Sergeant is a third year student in the Arts \& Science program at McMaster University. He has a wide variety of interests including pedagogy, psychology, health, and philosophy. Anand wrote this paper as a capstone project for a class on Technology and Society. He was interested in studying this topic because of its intriguing interdisciplinary relationships, and the relative lack of scholarly work in the novel field of virtual reality art and pedagogy. Anand is thankful to JIRR for providing the opportunity to share this work, and hopes that it may provide some interesting insight as artistic technologies continue to evolve. 


\section{Works Cited}

"400 Jaar Batavia Komt Met Virtual Reality Tot Leven in Westfries Museum." NH Nieuws, 28 May 2019, https://www.nhnieuws.nl/nieuws/246667/400-jaar-batavia-middels-virtual-reality-tot-leven-in-westfries-museum.

Bartels, Dennis M., and George E. Hein. "Learning in Settings Other Than Schools." Educational Researcher, vol. 32, no. 6, 2002, pp. 38-43., doi:10.3102/0013189x032006038.

Bayuni, Endy M. "COMmentARY: How Bad, How Cruel Were Dutch to Us?" The Jakarta Post, 23 Aug. 2018, https://www.thejakartapost.com/academia/2018/08/23/commentary-how-bad-how-cruel-weredutch-to-us.html.

"Batavia 1627 in Virtual Reality." Westfries Museum, https://wfm.nl/batavia-1627vr.

Bazin, Andre. What Is Cinema? Edited by Hugh Gray, 1967.

Benjamin, Walter. The Work of Art in the Age of Mechanical Reproduction. 1935.

Borg, Carmel, and Peter Mayo. "Museums: Adult Education as Cultural Politics." New Directions for Adult and Continuing Education, 127th ed., Wiley Periodicals, Inc., 2010, pp. 35-44.

Coates, Charlotte. "What Are the Best Examples of Virtual Reality in Museums?" MuseumNext, Nov. 2019, https://www.museumnext.com/article/how-museums-are-using-virtual-reality/.

Coffee, Kevin. "Cultural Inclusion, Exclusion and the Formative Roles of Museums." Museum Management and Curatorship, vol. 23, no. 3, 2008, pp. 261-279., doi:10.1080/09647770802234078.

Eggarxou, Demetra, and Sarantos Psycharis. "Teaching History Using a Virtual Reality Modelling Language Model of Erechtheum." International Journal of Education and Development Using Information and Communication Technology (IJEDICT), vol. 3, no. 3, 2007, pp. 115-121.

Freina, Laura, and Michela Ott. "A Literature Review on Immersive Virtual Reality in Education: State Of The Art and Perspectives." Institute for Educational Technology, CNR, Apr. 2015.

Gannon, Megan. "Virtual Reality Is Bringing These Lost Worlds Back to Life." NBCNews.com, NBCUniversal News Group, 17 Feb. 2017, https://www.nbcnews.com/mach/innovation/virtual-realitybringing-these-lost-worlds-back-life-n722006.

Goslin, Mike, and Jacquelyn Ford Morie. "Virtopia': Emotional Experiences in Virtual Environments." Leonardo, vol. 29, no. 2, 1996, pp. 95-100., doi:10.2307/1576338.

Hills-Duty, Rebecca. "National Museum of Finland Offers Virtual Time Travel." VRFocus, 16 Feb. 2018, https://www.vrfocus.com/2018/02/national-museum-of-finland-offers-virtual-time-travel/.

Kehoe, Marsely L. "Dutch Batavia: Exposing the Hierarchy of the Dutch Colonial City." Journal of Historians of Netherlandish Art, vol. 7, no. 1, 2015, doi:10.5092/jhna.2015.7.1.3.

Kelley, Brendan, and Cyane Tornatzky. "The Artistic Approach to Virtual Reality." The 17th International 
Conference on Virtual-Reality Continuum and Its Applications in Industry (VRCAI 19), 14 Nov. 2019, doi:10.1145/3359997.3365701.

Liu, James H., and Denis J. Hilton. "How the Past Weighs on the Present: Social Representations of History and Their Role in Identity Politics." British Journal of Social Psychology, vol. 44, no. 4, 2005, pp. 537-556., doi:10.1348/014466605x27162.

Mamdani, Mahmood. "Settler Colonialism: Then and Now." Critical Inquiry, vol. 41, no. 3, 2015, pp. 596-614., https://www.jstor.org/stable/pdf/10.1086/680088.pdf.

Mastandrea, Stefano, and Fridanna Maricchiolo, editors. The Role of the Museum in the Education of Young Adults. Motivation, Emotion and Learning. Rome TrE-Press, 2016, https://books.google.ca/books?i$\mathrm{d}=$ cuG2DwAAQBAJ\&dq=locher art learning\&source=gbs_navlinks_s.

Reyhner, John, and Navin Kumar Singh. "Cultural Genocide in Australia, Canada, New Zealand, and the United States: The Destruction and Transformation of Indigenous Cultures." Indigenous Policy Journal, vol. 21, no. 4, 2010, pp. 1-26., http://indigenouspolicy.org/index.php/ipj/article/view/23/7.

Sidarto, Linawati. "Dutch Museum Offers Virtual Reality Journey to Old Jakarta." The Jakarta Post, 21 Nov. 2019, https://www.thejakartapost.com/life/2019/11/21/dutch-museum-offers-virtual-realityjourney-to-old-jakarta.html.

Wright, Mary C. "Getting More out of Less: The Benefits of Short-Term Experiential Learning in Undergraduate Sociology Courses." Teaching Sociology, vol. 28, no. 2, Apr. 2000, pp. 116-126., doi:10.2307/1319259. 